\title{
ACR
}

Selected Papers of \#AolR2018:

The $19^{\text {th }}$ Annual Conference of the

Association of Internet Researchers

Montréal, Canada / 10-13 October 2018

\section{NAVIGATING NETWORKED TIME: VISUAL SELF-IDENTITY CONSTRUCTION AND MANAGEMENT AMONG YOUTH}

\author{
Michelle Gorea \\ Queen's University
}

\section{Visual Culture and Mediatization}

According to dominant theorizations of contemporary society, many people's daily practices now occur within, and reproduce, a social world where media are the fundamental reference and resource for the development of the self (Couldry \& Hepp, 2017, p.15). As a result, the ways people make sense of the world and the practices they enact are entangled within the constraints, affordances and power-relations that are characterized by 'deep-mediatization' (Couldry \& Hepp, 2017, p.7). As an important part of this continual mediation, the visual capacity of always present devices such as smartphones has increased the daily production and circulation of images of the self and others in social media, altering what and where images are made, and how they can be viewed and shared, making visual communication a far more routine activity in contemporary society (Gomez-Cruz \& Lehmuskallio, 2016).

Previous research has examined the incorporation of social media technologies into young people's lives (Livingstone \& Sefton-Green, 2016), focusing on the dynamics of generational use and interaction (boyd, 2014), relationship maintenance (Baym, 2015), and identity formation (Turkle, 2012). This has revealed the mutual shaping of technologies, interaction, and identity in the broader contexts of economic and social change related to 'millennials'. Although there is literature surrounding youths' social media practices, there is little work that focuses on the precise ways that daily visual practices get reworked into their conceptualizations of time, self-development and selfidentity. This work in progress paper is a component of a broader study, which focuses on: how the curation and circulation of images may be shaping how youth manage and negotiate their identities; the extent to which socio-economic differences frame youths' encounters with, and understandings of, visual images; and the different practices that visual media devices allow, encourage, or constrain and how this may be creating scripts for behavior.

This paper explores three key questions:

Suggested Citation (APA): Gorea, M. Navigating Networked Time: Visual Self-Identity Construction And Management Among Youth. (2018, October 10-13) Paper presented at AolR 2018: The 19th Annual Conference of the Association of Internet Researchers. Montréal, Canada: AolR. Retrieved from http://spir.aoir.org. 


\section{ACR}

Selected Papers of \#AolR2018:

The $19^{\text {th }}$ Annual Conference of the

Association of Internet Researchers Montréal, Canada / 10-13 October 2018

1) What happens when visuality becomes a part of youth's everyday practices of interaction?

2) What roles are images playing in routine interaction among youth?

3) How and in what ways does the maintenance of a visually 'mediated presence' in social media shape youths' views of the self?

These questions are important to consider because as smartphones continue to mediate youth's daily practices, images are increasingly conceptualized as meaningful modes of personal expression and identity construction (Hand, 2017, p. 221).

\section{Methods}

I will be reporting on emerging findings from a social media content analysis and indepth interview data. Participants included me as a contact within their social media feeds enabling me to collect and analyze the images they posted on a daily basis before the in-depth interview. Semi-structured interviewing was used to gain detailed understanding of the rationales different youth have for making, sharing and viewing images, whether they consider them to be significant and in what ways, how they understand the expectations for communicating visually, and to what extent they try to adapt and negotiate their immersion in visual social media. Purposive sampling was used to recruit participants that reflect the broader demographic of several neighborhoods, capturing variation in socio-economic status, gender, age but also variations in material infrastructure (devices owned, access to wifi, data plans). 35 youth were interviewed between the ages of 15-22 from May 2017 through February 2018.

\section{Findings}

This paper elaborates on findings within three categories that illustrate youth's visual practices and how they are differently understood over time: (1) images of the self in the moment; (2) images of the self over time; and (3) images of the self under surveillance.

Firstly, I discuss the ways that participants use images as a primary vehicle for immediate identity expression and social judgment. Some youth understand images as extensions of themselves and closely tied to their senses of not only who they are, but also who other people might be. Through visual communication, the self is revealed in the moment. For instance, some youth monitor people's personalized digital avatar (Bitmoji) in real-time/location and accordingly change their behaviour based on this information. Similar to recent research (Tiidenberg, 2018; Warfield, 2017), several rules for appropriate immediate visual communication emerged. Such as excluding repetitive images and overly edited photos, and displaying interesting activities/events. The 


\section{ACR}

Selected Papers of \#AolR2018:

The $19^{\text {th }}$ Annual Conference of the

Association of Internet Researchers

Montréal, Canada / 10-13 October 2018

increased pace and ubiquity of images coupled with the activity of looking adds a new component to the pre-existing pressures that youth feel regarding self-image and reputation.

Secondly, looking back at one's visual self over time was significant. Some youth commonly scroll back through images as a method of remembering and nostalgia, often with friends. The practice of regularly removing images was also common. A 'silly' image or a photograph of an ex-relationship was often perceived as requiring removal in order to portray a valid representation of 'real life'. However, a common sentiment was that the images people post on social media are not representative of 'real life'-as pictures of happiness and enjoyment are often posted when one is sad. This may prompt actions such as social media 'cleanses' and 'breaks', thus expressing youths' broader desire to maintain a coherent idealized self-image both across platforms and within their daily lives.

Thirdly, I discuss how some participants' perceived parental approval of their social media image is an important form of self-surveillance, shaping decisions about image posting in social media. Some older youth seek approval of their image by asking friend's opinions regarding what to post. Embodying an older notion of surveillance, others routinely used the "Find my Friends" app to ensure their friends were safe, and not making a 'fool' of themselves in vulnerable situations. The findings indicate that some youth adjust their behaviour according to a perceived parental gaze while others self-survey themselves and those within their friend network for safety purposes.

\section{Discussion}

The preliminary findings of this research suggest that although youth's technological practices may not all be new, there are significant aspects of visuality that alters some of the key factors shaping youths' use and understandings of new media technologies. Visuality creates new knowledges and practices surrounding factors such as: age, socioeconomic status, peer group, and self-image. This results in youth not only having to manage these factors, but also engage in a variety of strategies to navigate the visibility of their digitally mediated lives.

\section{References}

Baym, N. (2015). Personal Connections in the Digital Age. 2nd ed. Cambridge: Polity.

boyd, d. (2014). It's complicated: The social lives of networked teens. New Haven: Yale University Press. 


\section{AOR}

Selected Papers of \#AolR2018:

The $19^{\text {th }}$ Annual Conference of the

Association of Internet Researchers Montréal, Canada / 10-13 October 2018

Couldry, N., \& Hepp, A. (2017). The Mediated Construction of Reality. Cambridge: Polity.

Gómez Cruz, E., \& Lehmuskallio, A. (Ed.). (2016). Digital Photography and Everyday Life, London: Routledge.

Hand, M. (2017). Visuality in Social Media: researching images, circulations, and practices. In L. Sloan and A. Quan-Haase (Eds.), The Sage Handbook of Social Media Research Methods (pp. 215-231). London: Sage.

Livingstone, S., \& Sefton-Green, J. (2016). The Class: Living and Learning in the Digital Age. New York: New York University Press.

Tiidenberg, K. (2018). Selfies: Why We Love (and Hate) Them. United Kingdom:

Emerald Publishing.

Turkle, S. (2012). Alone Together. New York: Basic Books.

Warfield, K. (2017). "I Set the Camera on the Handle of My Dresser": Re-Matter-lalizing Social Media Visual Methods through a Case Study of Selfies. Media and

Communication, Vol. 5 (4): 65-74. 